DR. DOMINGO BARBER HERNÁNDEZ (Orcid ID : 0000-0002-5488-5700)

Article type : Original Article: Experimental Allergy and Immunology

\title{
Multi-omics Analysis Points to Altered Platelet Functions in Severe Food-Associated Respiratory Allergy
}

D. Obeso ${ }^{1,2^{*}}$ MSc, L. Mera-Berriatua ${ }^{1^{*}}$ MSc, J. Rodríguez-Coira ${ }^{1,2}$ MSc, D. Rosace ${ }^{1}$ MSc, P. Fernandez ${ }^{1}$ PhD, I. Martin-Antoniano ${ }^{1,4}$ PhD, M. Santaolalla ${ }^{8}$ MD, PhD, G. Marco Martín ${ }^{5}$ MD, PhD, T. Chivato ${ }^{1,4}$ MD, PhD, M. Fernández-Rivas ${ }^{5} \mathrm{MD}, \mathrm{PhD}, \mathrm{T}$. Ramos $^{6} \mathrm{MD}, \mathrm{PhD}, \mathrm{C}$. Blanco ${ }^{6} \mathrm{MD}$, PhD, M.I. Alvarado MD, PhD, C. Domínguez ${ }^{7}$ MD, S. Angulo ${ }^{9} \mathrm{MSc}, \mathrm{C}$. Barbas ${ }^{2} \mathrm{PhD}, \mathrm{D}$. Barber ${ }^{1} \mathrm{PhD}, \mathrm{A}$. Villaseñor ${ }^{1,2 \#} \mathrm{PhD}$, MM. Escribese ${ }^{1,3 \#}$ PhD.

${ }^{1}$ IMMA, Instituto de Medicina Molecular Aplicada, Facultad de Medicina, Universidad San Pablo CEU, Madrid, España.

${ }^{2}$ CEMBIO, Centro de Excelencia en Metabolómica y Bioanálisis, Facultad de Farmacia, Universidad San Pablo CEU, Madrid, España.

${ }^{3}$ Departamento de Ciencias Médicas Básicas, Facultad de Medicina, Universidad San Pablo CEU, Madrid, España.

${ }^{4}$ Departamento de Ciencias Médicas Clínicas, Facultad de Medicina, Universidad San Pablo CEU, Madrid, España.

${ }^{5}$ Hospital Universitario Clínico San Carlos, Madrid, España.

${ }^{6}$ Hospital Universitario de La Princesa, Instituto de Investigación Sanitaria Princesa (IP), Madrid, España.

${ }^{7}$ Hospital Virgen del Puerto, Plasencia, Cáceres, España.

${ }^{8}$ Hospital Universitario HM Sanchinarro, Madrid, España.

${ }^{9}$ Departamento de Matemática Aplicada y Estadística, Universidad San Pablo CEU, Madrid, España.

*, \# These Authors have equally contributed

This article has been accepted for publication and undergone full peer review but has not been through the copyediting, typesetting, pagination and proofreading process, which may lead to differences between this version and the Version of Record. Please cite this article as doi: $10.1111 /$ all.13563

This article is protected by copyright. All rights reserved. 


\section{Corresponding author:}

Domingo Barber, $\mathrm{PhD}$

IMMA, Instituto de Medicina Molecular Aplicada, Facultad de Medicina, Universidad San Pablo CEU, Avda. Monteprincipe s/n

28668 Boadilla del Monte, Madrid, España.

TIf: 913724700 ext. 4662

E-mail: domingo.barberhernandez@ceu.es

\section{Author Contributions}

*, \# These Authors have equally contributed

D.B. was the PI and together with C.Barbas, M.M.E., T.Ch. and A.V. designed and supervised the research. D.O. performed the metabolomics analysis and data treatment. L.M-B. performed the transcriptomic analysis and data treatment. J.R-C., D.R., P.F. and I.M-A. contributed to the metabolomics and transcriptomics biological interpretation. M.S., G.M., M.F.R., T.R., C. Blanco, M.I.A. and C.D. included all study patients. S.A. supervised statistical analysis. All authors contributed to the writing of the manuscript and have given approval to the final version of the manuscript.

\section{Sources of funding for the research reported in the article:}

This work was supported by ISCIII (Project numbers, PI16/00249 and PI15/02256) cofounded by FEDER for the thematic network and co-operative research centers ARADyAL RD16/0006/0015, RD16/0006/009. D.O., L.M.B. and D.R. are supported by FPI-CEU predoctoral fellowships and A.V. is funded by a postdoctoral research fellowship from ARADyAL.

Short title: Omics combined analysis in severe allergy

Key words: Food allergy, metabolomics, platelets, respiratory allergy, transcriptomics.

This article is protected by copyright. All rights reserved. 


\section{Abbreviations:}

ARA: Arachidonic acid

FC: Fold change

GC-MS: Gas chromatography coupled to mass spectrometry

GSEA: Gene Set Enrichment Analysis

IPA: Ingenuity Pathway Analysis

LC-MS: Liquid chromatography coupled to mass spectrometry

LPCs: Lysophosphocholines

MS/MS: Tandem Mass Spectrometry

PBMCs: Peripheral blood mononuclear cells

QC: Quality control

RT: Retention Time

S1P: Sphingosine-1-phosphate

\section{ABSTRACT}

Background: Prevalence and severity of allergic diseases have increased worldwide. To date, respiratory allergy phenotypes are not fully characterized and, along with inflammation progression, treatment is increasingly complex and expensive. Profilin sensitization constitutes a good model to study the progression of allergic inflammation. Our aim was to identify the underlying mechanisms and the associated biomarkers of this progression, focusing on severe phenotypes, using transcriptomics and metabolomics.

Methods: 25 subjects were included in the study. Plasma samples were analyzed using Gas and Liquid Chromatography coupled to Mass Spectrometry (GC-MS and LC-MS, respectively). Individuals were classified in 4 groups - "non-allergic", "mild", "moderate" and "severe" - based on their clinical history, their response to an oral challenge test with profilin, and after a refinement using a mathematical metabolomic model. PBMCs were used for microarray analysis.

This article is protected by copyright. All rights reserved. 
Results: We found a set of transcripts and metabolites that were specific for the "severe" phenotype. By metabolomics, it was detected a decrease in carbohydrates and pyruvate and an increase in lactate, suggesting aerobic glycolysis. Ohter metabolites were incremented in severe group: lysophospholipids, sphingosine-1-phosphate, sphinganine-1-phosphate, as well as lauric, myristic, palmitic, and oleic fatty acids. On the other hand, carnitines were decreased along severity. Significant transcripts in the "severe" group were downregulated and were associated to platelet functions, protein synthesis, histone modification and fatty acid metabolism.

Conclusions: We have found evidence that points to the association of severe allergic inflammation with platelet functions alteration, together with reduced protein synthesis, and switch of immune cells to aerobic glycolysis.

\section{INTRODUCTION}

Allergic diseases affect more than a quarter of the population and present an increasing trend. It is possible that in a near future, economic impact of allergy might reach a non-maintainable cost. Consequently, it is pivotal to unravel the mechanisms involved in this process in order to develop new diagnostic, intervention and prevention strategies. However, one of the main problems found in the quest for these new strategies is the difficulty of having properly clinically-stratified patients that can be used for the development of accurate models.

In the last years, component-resolved diagnosis strategies (1) have allowed a significant increase in the understanding of allergic disease evolution. In this context, molecular-based epidemiological studies performed in Spain (2-4) allowed the identification of different clinical phenotypes of the dominant pollen allergies (olive and grass pollen). In areas of extreme pollen exposure, patients often display a more severe phenotype (5). In fact, some grass-pollen-allergic patients resident in highly exposed regions can develop severe food-allergic reactions mediated by profilin (6), a type of reaction hardly seen in other grass pollen-exposed territories. Profilin has proved to be a clinically relevant aeroallergen $(7,8)$ able to induce strong T cell proliferation (9). Recently, it has been proved that evolution towards severity in the profilin food allergy model is associated to a progressive rise in effector cell sensitivity, immune cells infiltration in the epithelia and structural remodeling of the oral mucosa (10). This provides evidence that oral mucosa may play a key role in both food allergic

This article is protected by copyright. All rights reserved. 
reactions and respiratory-to-food allergy evolution. Moreover, severe profilin reactors express relatively high levels of periostin, a biomarker linked to airway inflammation and remodeling (11).

As a consequence, the group of severe reactors to profilin provides a unique clinical model for understanding allergy progression and associated barrier inflammation. Moreover, by mean of integrated -omics approaches, new potential diagnostic strategies connected with progressive allergic endo-phenotypes can be uncovered. This is a clear unmet need in allergy research. (12)

The -omics sciences have emerged as a new strategy to study living organisms. They offer the possibility of a better understanding of a disease by obtaining vast amounts of data from every individual biological sample. Transcriptomics, and to a lesser extent metabolomics, have been previously used to uncover the molecular mechanisms involved in the development of several allergic diseases (13-20). Previous studies have not yet addressed neither specific allergic phenotypes nor their associated metabolic signatures, and these are still largely unknown. Therefore, the combination of both -omics platforms used in the present work offers an opportunity to characterize allergic phenotypes.

\section{MATERIALS AND METHODS}

\section{Patients}

Twenty-five individuals (aged 18-55) were recruited between January 2013 and January 2016. All subjects provided written informed consent. The protocol was approved by the Committees of Research and Ethics from the participant Hospitals. These patients had been deeply studied for oral mucosa remodeling in a previous study (10). From these, six subjects were non-allergic and used as controls. All patients were interviewed to establish their clinical history. Inclusion criteria for allergic patients were: a positive skin prick test to profilin but negative to Lipid Transfer Proteins commercially available extracts, positive specific IgE to profilin (>0.35 kU/L), but negative to both Pru p 3 and Bet v 1, (ImmuneCAP and ISAC CAP, Thermo Fisher Scientific) (Supplementary Information SI, Table 1S). Patients underwent an oral challenge using a pure profilin extract. Clinical status was determined by the clinical history of food allergy and the outcome of the oral challenge. Patients who suffered systemic reactions affecting several organs like urticaria and asthma were phenotyped as "severe profilin-allergic patients" $(n=6)$. Patients who presented local or subjective reactions

This article is protected by copyright. All rights reserved. 
during oral challenge such as OAS, angioedema or oral pruritus, were considered as "Non-severe profilin-allergic patients" ( $n=12$ ). Individual data are included in the (Table 2S).

Allergic patients who had received any pollen extract immunotherapy in the last 5 years, or presented uncontrolled asthma, were excluded.

\section{Sample Collection and Processing}

Whole blood was drawn before the profilin challenge and was divided into two tubes: one for plasma extraction and another for PBMCs isolation. Briefly, $20 \mathrm{ml}$ of peripheral blood were collected to obtain plasma by centrifugation and PBMCs using Ficoll-Paque (GE Healthcare ${ }^{\mathrm{TM}}$ ) density gradient centrifugation. Samples were stored at $-80{ }^{\circ} \mathrm{C}$ until metabolomic and transcriptomic analyses were performed.

\section{Metabolomic analyses}

Plasma samples were measured using a multiplatform analysis: Liquid and Gas Chromatography coupled to Mass Spectrometry (LC-MS and GC-MS, respectively). Both techniques followed previously described methodologies $(21,22)$. Full descriptions of sample preparation, instrumental description, data treatment and metabolite identification are available in SI-Part 1. The data is available at Metabolomic Workbench platform (access number ST000980).

\section{Statistical analyses}

Multivariate analysis was performed using SIMCA P+14.0 (Umetrics, Umeå, Sweden). Principal Component Analysis (PCA), a non-supervised model, was used to observe data patterns. Likewise, Orthogonal- and Partial-Least-Square Discriminant Analysis models (OPLS-DA and PLS-DA, respectively), which are supervised models, were used to test real differences between the case groups. For LC-MS data, logarithmic transformation and center scaling were used, whereas for GCMS, unit variance scaling was applied to all variables. Robustness of the models was evaluated based on $R^{2}$ (explained variance) and $Q^{2}$ (capability of prediction) scores $(23,24)$. Regarding OPLS-DA, the variability between groups was explained only by the separation in the $\mathrm{X}$-axis, while the $\mathrm{Y}$-axis was not related (or orthogonal). This was validated by the cross-validation tool (24) and by the "leaving- 
1/3-out" approach (25). Differences among the experimental groups were tested using the nonparametric Kruskal-Wallis test with a Benjamini-Hochberg $(\mathrm{BH})$ correction in order to identify potential biomarkers. Additionally, significant differences between "mild vs severe" and "moderate vs severe" using U-Mann Whitney test with a BH p-value correction were added, in order to improve the biological interpretation. Statistical significance was set at $95 \%$ level $(p<0.05)$. Statistical analyses were performed using Matlab R2015a (Mathworks) software. The MetaboAnalyst online tool was used for heatmaps and hierarchical clustering.

\section{Transcriptomic analysis}

RNA extraction: quantitation and integrity check

RNA was extracted from Ficoll ${ }^{\circledR}$-isolated PBMCs using RNeasy ${ }^{\circledR}$ Mini Kit (Qiagen) with DNase treatment following manufacturer procedure. RNA concentration was determined using a NanoDrop ${ }^{\mathrm{TM}}$ 2000/2000c Spectrophotometer and its quality was assessed with Experion RNA StdSens analysis kit (Bio-Rad), establishing RQI as an indicator of quality. Following manufacturer recommendations, those samples with an $\mathrm{RQI} \geq 7$ were selected for the microarray experiments. Samples p2 and p3 from the "non-allergic group" and p24 from the "severe group" did not satisfy quality requirements and were excluded from transcriptomic analysis.

\section{Microarray target preparation and hybridization}

The gene expression profile of the samples was analyzed using GeneChip Human Gene 2.1 ST strips (Affymetrix, Thermo Fisher Scientific). Following manufacturer instructions, $100 \mathrm{ng}$ of RNA from each sample were hybridized using GeneChip ${ }^{\text {TM }}$ WT PLUS Reagent Kit. Details of hybridization are found in SI-Part 2.

\section{Analysis of results}

CEL raw files were normalized and transformed into expression measures using Expression Console Software (Affymetrix). The Robust Multi-array Average (RMA) algorithm was used for background correction, normalization, and summarization of probe-set level expression of the samples.

This article is protected by copyright. All rights reserved. 
Gene-level expression analysis was performed using the refined metabolomic classification, with Transcriptome Analysis Console (Affymetrix). A gene was considered differentially expressed if it had a fold change (FC) higher than 2 or lower than -2 with an ANOVA $p$ value $<0.05$.

The pathways involved were acquired by Ingenuity Pathway Analysis (IPA, Qiagen). Gene Set Enrichment Analysis (GSEA) of the RMA normalized samples was performed using the following parameters: number of permutations $=100$, collapse dataset to gene symbols=true and permutation type=phenotype. Raw data can be found on the GEO database (access number GSE114707).

qRT-PCR analysis

Twenty genes related to the main significant pathways found with GSEA and IPA (inflammatory response, platelet functions, fatty acid metabolism and histone modification) were selected for validation studies by quantitative RT-PCR (qRT-PCR, Table 3S).

High Capacity RNA to cDNA Kit (Applied Biosystems) was used for the validation according to the manufacturer instructions, briefly; $1 \mu \mathrm{g}$ of total RNA was reverse transcribed in a final volume of 20 $\mu \mathrm{L}$. Primers were designed using OligoArchitect ${ }^{\mathrm{TM}}$ (Sigma Aldrich) and qRT-PCR was performed using SYBR Green master mix (Takara) in the equipment Real Time HT 7900 (Applied Biosystems). Reactions were run in triplicate. Expression data were normalized to the median of housekeeping gene $B 2 M$ and the results were analyzed using the $2-\triangle \Delta C T$ method (26). Details are found in SI-Part 2.

\section{RESULTS}

Metabolic profiling and patient classification.

Metabolomic profiles of plasma samples were obtained using LC-MS and GC-MS. Initially, from 615 and 506 chemical signals obtained by LC-MS in positive and negative ionization modes, respectively, 349 and 400 complied with the quality criteria. In addition, 95 metabolites per sample were obtained using GC-MS. Data quality was assessed by clustering quality control (QC) measurements in a non-supervised model using PCA for the three techniques (Figure 1S). Trends of the samples were examined; as an example, the PCA model from LC-MS data in positive mode showed no clear clustering of patients according to their clinical status (Figure 1A). However, individuals with a clear

This article is protected by copyright. All rights reserved. 
clinical status -"non-allergic" and "severe profilin-allergic patients"- were modeled using a supervised model. Therefore, in order to obtain the differences exclusively according to the class (27), an OPLS-DA model was performed (Figure 1B). This model showed good quality parameters $\left(\mathrm{R}^{2}\right.$ $\left.=0.99, Q^{2}=0.75\right)$ and was validated using the "1/3-out" approach, showing a prediction accuracy of 92\% and was used to assign a class to "Non-severe profilin-allergic patients" (Figure 1B), following a similar approach to other authors (28-30). Samples were grouped within circles according to the OPLS-DA mathematical algorithm (Table 4S). Patients with a predicted score higher than 0.75, related to non-allergic, were classified as "mild". Those with a score higher than 0.75 , closer to "severe profilin-allergic patients", were classified as "severe", whereas the rest of the samples were classified as "moderate". Consequently, four groups were stratified: "non-allergic", "mild", "moderate" and "severe". To sum up, the model allowed the classification of "Non-severe profilinallergic patients" that could not be properly classified in the oral challenge setup.

Samples were plotted according to their metabolomic classification using a PCA model, which showed a clear tendency to separate the "mild" group from the "severe" and "moderate" groups (Figure 1C). Furthermore, aiming to show the differences between groups, discriminant analysis using PLS-DA was performed for each pair of groups (Figure 2S). The results produced at least one model for each pairwise comparison with high quality parameters. These results demonstrated that there are metabolic differences between the groups.

\section{Metabolic description between allergic phenotypes}

After multivariate analysis, significant variables were selected using univariate analysis. The numbers of significant variables between groups were summarized using Venn diagrams. More differences were observed between "mild vs severe" than between "severe vs moderate" phenotypes (Figure 2A). Moreover, FC was represented by heatmaps using hierarchical clustering within the allergic groups (Figure 3S). Overall results suggest that there are specific features which can characterize each phenotype, especially the "severe".

Once significant features in LC-MS were found, identification through MS/MS fragmentation was performed. Together with GC-MS metabolites, a total of 74 compounds were listed (Table 5S), encompassing carbohydrates, sphingolipids, lysophospholipids, carnitines, amino acids, fatty acids and organic acids. Their FCs were calculated in the pairwise comparisons and summarized in Table 6S. Most of the metabolites presented increased levels in "severe" compared to "mild" group $(n=49)$.

This article is protected by copyright. All rights reserved. 
The general observed changes in the "severe group" were: decreased levels of hexoses, pentoses, pyruvate and sphinganine-C17; an increase along severity in the levels of, most lysophosphocholines (LPCS), sphingosine-1-phosphate (S1P), sphinganine-1-phosphate and lactate. Furthermore, fatty acids such as myristic and lauric acid were diminished in "mild" and "moderate", and increased in the "severe" group. Trajectories of these metabolites are shown in Figure 2B.

\section{Gene expression analysis}

From the 48226 transcripts analyzed, 596 transcripts were identified as significantly differently expressed between the experimental groups (Figure 3A). These differences were depicted in Venn diagrams. Major differences were observed between allergic phenotypes, especially in the "severe vs mild" comparison, with 220 differentially expressed transcripts (Figure 3A), and between "severe vs moderate", with 87 (Figure 3B). Validation of the transcriptomic analysis was assessed by qRTPCR, where $95 \%$ of selected transcripts showed the same expression pattern as in the microarray experiments. Thus, the results obtained can be considered reliable (Figure 4S).

Afterwards, we selected the 100 most differentially expressed genes to depict a heatmap (Table 7S). Transcripts were classified into four clusters according to their expression pattern (Figure $3 \mathrm{C}$ ). Cluster 1 - upregulated in the "severe" phenotype and downregulated in "mild" - contained essentially H/ACA box snoRNAs (SNORA). Cluster 2 - which was downregulated in the "mild" group included a heterogeneous group of genes. Cluster 3, - decreased in severe patients with respect the other groups and thus constituted the best bio-markers for the "severe" phenotype - includes genes closely related to coagulation and histone modifications. Finally, cluster 4 - where genes were downregulated in "severe" compared to the "mild" group - contained small nucleolar RNAs (snRNA), their variants, and genes related to protein biosynthesis and growth factors.

\section{"Severe" patients display a differential transcriptomic profile}

We performed pathway analysis aiming to match the characteristic genes of the "severe" profile with associated biological processes. Two types of complementary analyses were carried out. First, we compared separately "severe versus mild" (Table 8S-A) and "severe versus moderate" (Table 8SB) using GSEA. Then, we repeated the analysis of the previous comparisons with IPA (Table 1). GSEA results indicated that the pathways of: DNA reparation, inflammatory response, oxidative 
phosphorylation, fatty acid metabolism, the complement system, and coagulation; were negatively correlated with the "severe" phenotype. Likewise, IPA obtained pathways related to: endothelial cells, platelet phagocytosis and platelet functions - such as activation and, binding and adhesion, among others -. Additionally, the activation state (Activation Z-score) of the significant pathways, which can be positive - pointing to pathway activation - or negative - for inactivation -, was measured. Most of these functions had a negative value for "severe" patients (Table 1).

These results suggest that coagulation and platelet related pathways are downregulated in "severe" patients and might be their specific transcriptomic profile. Moreover, pathways and transcripts related to fatty acid metabolism and histone modification were increased in "mild" and "moderate" groups while decreased in "severe" phenotype.

Severe allergic phenotypes present altered platelet functions.

Taking into account these findings, we decided to focus on coagulation and platelet related transcripts. Specifically, those transcripts observed as statistically significant for IPA software, and genes related to platelet functions (Figure $3 \mathrm{C}$ ), were analyzed.

The trajectories among the groups were plotted to corroborate that the selected genes had a different expression pattern in the "severe" phenotype (Figure 4). The plots showed a significant decrease in the expression of these genes in the "severe" group compared to the rest. Among them there were genes related to platelet-adhesion (GP1BA, GP9, GP6 and SELP); activation (P2RY12, ALOX12 and PTGS2); both shape change and granule secretion (MYL9 and SDPR) (31); aggregation (ITGB3, ITGA2B and TREML1) (32); as well as other genes related to platelet functions (PPBP, CLU, and $N R G N)(33,34)$. These transcripts and their platelet-associated functions were represented in Figure 5 in order to have a better understanding of platelet dysfunctions in the "severe" phenotype.

Regarding metabolomics, we also observed some metabolic changes related to platelet activation: S1P and LPs were incremented in the "severe" group compared to the intermediate allergic phenotypes ("mild" and "moderate"), while sphingosine was decreased (Figure 2B). An integrated

This article is protected by copyright. All rights reserved. 
view of both metabolomic and transcriptomic changes supporting altered platelet functions in "severe" allergic individuals is represented in Figure 5.

\section{Discussion}

Finding suitable clinical models of allergy disease progression is not easy. In particular, identifying homogeneous severe allergic phenotypes, which are critical to understand allergy evolution, is an arduous task. We took advantage of the unique model that these grass-pollen-allergic patients represent - those resident in high pollen exposure areas who develop severe food allergic profilinmediated reactions - These reactions identify a patient group with a severe allergic phenotype that apparently loses tolerance to the allergen.

The aim of this work was both to identify potential biomarkers as well as to understand underlying causes for severity progression. We used a combined approach of two -omics, metabolomics and transcriptomics, and generated a model for patient classification.

Previous studies have shown that the use of mathematical algorithms based on objective parameters -such as transcriptome profiles- is useful to improve the clinical classification of patients (28-30). In this work, we have established a classification based on the metabolic profile of the patients. First, we included non-allergic subjects and identified severe allergic phenotypes by their clinical history and their response to the oral challenge test with pure profilin. By using these two extreme phenotypes, we obtained a mathematical algorithm that was used to refine the clinical classification of the "Non-severe profilin-allergic patients". It is important to point out that these phenotypes cannot be perfectly classified upon oral provocation, as many times the provocation procedure must be stopped due to intense local reactions (35). This new classification represents a potential tool for patient stratification that should be validated in further studies, and is in line with current approaches to understand disease phenotypes (28-30). This allowed us to analyze the evolution of allergic inflammation along severity. Interestingly and unexpectedly, all patients that were clinically classified as "severe" shared common metabolomic and transcriptomic profiles, thus confirming the correlation between clinical and-omics classification.

This article is protected by copyright. All rights reserved. 
Afterwards, we performed data analysis of both -omics to find out specific signatures, to identify biomarker candidates and biological pathways associated with the acquisition of a severe phenotype. The different metabolite levels and transcript expression kinetics provided a global view of the biological processes associated to inflammation evolution.

The first set of downregulated transcripts in "severe" patients consisted of DDX11L2 and MT-TR, which are involved in translation initiation, nuclear and mitochondrial splicing, and ribosome- spliceosome assembly (36). In parallel, we observed an increase in urea, suggesting an increase in protein catabolism.

Marked changes in cell energy metabolism were also found. Hexoses, pentoses and pyruvate are consumed and metabolized into lactate in the presence of oxygen. In agreement with our results, existing -omics-based studies have reported that immune cells change their metabolism to cope with the increasing demand resulting from the need to synthetize biological precursors. This is known as "aerobic glycolysis" or "Warburg metabolism" $(37,38)$ and has been described in tumoral cells, asthma and inflammation (39-41). Furthermore, with GSEA, we also identified different biological processes reduced in "severe" patients: such as oxidative phosphorylation, fatty acid metabolism and adipogenesis (Table 8S); all supporting the switch to Warburg metabolism.

Analyzing lipid metabolism, we observed a progressive increase of arachidonic acid (ARA) precursors - palmitic and oleic acids - among allergic phenotypes. Meanwhile, shorter fatty acids - myristic and lauric acids - were decreased in the intermediate phenotypes ("mild" and "moderate") but increased in the "severe" group. Furthermore, carnitines levels followed a reduction trend along severity. In contrast, we did not see changes in the levels of ARA between groups, matching previous reports in which exposure to allergens did not change the levels of this fatty acid in plasma (20). One possible explanation for these results is that, instead consuming the fatty acids by beta-oxidation, they are likely being used for the synthesis of inflammatory mediators (42-43). Perhaps, the most interesting metabolic signature is related to sphingolipids. We detected a progressive increase of S1P - a key mediator that exerts multitude of effects in different tissues - with severity. S1P is capable of regulating gene transcription by inhibiting histone deacetylases (45), which concurs with the downregulation of histone modification related genes $(H I S T 1 H 2 B H$ and HIST1H3H). These had a

This article is protected by copyright. All rights reserved. 
negative association with DNA repair in the "severe" phenotype (46), suggesting modifications in epigenetic regulation networks.

Interestingly, we have identified a set of downregulated transcripts involved in platelet functions: formation of adhesion complexes (GP1BA and GP9, SELP); receptors (GP6, P2RY12) (47); aggregation of complexes (ITGB3, ITGA2B) (48); synthesis of HETE-12 and Thromboxane A2 (ALOX12, PTGS2) (49); and both shape change induction and granule secretion processes (MYL9, SDPR, RAB27B) (50, 51). Moreover, in the GSEA and IPA analyses, several pathways related to platelets and coagulation were significantly downregulated in the "severe" group. Aligned with these findings, we have observed different metabolic changes. We detected a decrease of sphingosine and xenosphingolipids (sphinganine-C17) in the "severe" group. Sphingosine is a precursor of S1P, and their decreased levels along severity suggest a continuous biosynthesis of S1P. Furthermore, in a recent study, an inverse association of intestinal microbial-derived sphingolipids with childhood food allergy was established, highlighting the importance of those metabolites in the allergic disease (52). In addition, different studies have demonstrated that S1P has a role in inflammation and that activated platelets are able to produce, store, and release it by an $A B C$ transporter (53-56). Besides, S1P can be degraded by the LPP1 platelet outer surface receptor (57) (Figure 5). Finally, we observed an increase along severity of lysophospholipids (LPCS, LPS and LPEs), as other authors have previously described in asthma and other inflammatory pathologies (17, 20, 58-60). These lysophospholipids and ARA precursors, increased in "severe" patients, are involved in platelet activation in inflammatory environments (61). Recent evidence revealed that the lung is a site of platelet biogenesis and a reservoir for hematopoietic progenitors (62). This creates a whole range of new possibilities for understanding the role of platelets in airway inflammation. Our findings point to platelet dysfunction in the "severe" phenotype (Figure 5).

These findings open up the possibility for considering new intervention strategies oriented to the stabilization of inflammation/repair systems, e.g. by using supplement-based interventions to replenish metabolic precursors that are highly consumed, as other studies have pointed out for asthma and allergy $(19,63-65)$. Altered energy metabolism could also constitute a pharmacological target. Understanding in detail the role of platelets could become a completely different approach to control severe allergic phenotypes.

This article is protected by copyright. All rights reserved. 
The combined analysis of transcripts and metabolic alterations in allergic patients that have been stratified based to their severity sheds some light on the progression of this pathology. Interestingly, the role of platelets in inflammation and related pathologies, such as cancer and autoimmune diseases, has been already suggested (66-71). We describe new mechanisms, pointing to platelet dysfunction, reduced protein synthesis, and a switch to Warburg metabolism, that are associated to severe allergic inflammation. Further studies in other severe allergy models, together with prognosis strategies based on the omics approaches, will allow for a better comprehension of the complex network between platelets and the immune system.

\section{Conflict of Interest Statement}

Domingo Barber has received consultancy fees from ALK and Aimmune therapeutics companies. Tomás Chivato has received lecture fees from URIACH and FAES laboratories. Montserrat Fernández Rivas consulting fees from Aimmune, DBV, Schreiber Foods, and lecture fees from ALK, Allergy Therapeutics and Thermofisher Scientific. The rest of the Authors have no conflict of interest. All authors have read and approved the manuscript.

\section{Acknowledgments}

We would like to thank all institutions and hospitals involved: Institute of Applied Molecular Medicine (IMMA, San Pablo CEU University, Madrid), Centre for Metabolomics and Bioanalysis (CEMBIO, San Pablo CEU University, Madrid), Clínico San Carlos University Hospital (Madrid, España), La Princesa University Hospital (Madrid, España), HM Sanchinarro University Hospital (Madrid, España) and Virgen del Puerto Hospital (Plasencia, España). Authors also acknowledge Tomás Barker-Tejeda, for his asserted comments.

\section{Figure Legends}

Figure 1. Unsupervised and supervised multivariate analysis of LC-MS positive mode data used for refined classification of "Non-severe profilin-allergic patients". A. PCA model of the sample set (Key: "non-allergic" (•; green circle), "Non-severe profilin-allergic patients" (苂; blue square), "severe profilin-allergic patients" ( $\mathbf{\Delta}$; red triangle). B. OPLS-DA prediction model; $\mathrm{R}^{2}=0.99, \mathrm{Q}^{2}=0.75$ (Key: workset samples (green circle • - "non-allergic" subjects; red triangle $\mathbf{\Delta}$ - "Severe profilin-allergic patients"), prediction set samples (blue square - - "Non-severe profilin-allergic patients"). C. PCA 


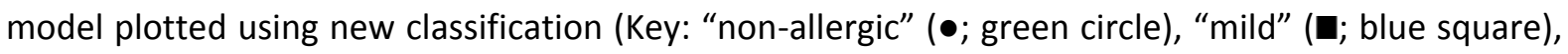
"moderate" ( ; black pentagon), "severe" ( $\mathbf{\Delta}$; red triangle). Log transformation and centre scaling was used for the models.

Figure 2. Statistical significant differences between the groups within the three techniques. A. Venn diagrams representing the differences in each group against the rest: "non-allergic vs mild" (blue), "non-allergic vs moderate" (red), "non-allergic vs severe" (brown), "mild vs moderate" (yellow) and "moderate vs severe" (purple). B. Trajectories of representative metabolites classified according their biochemical groups: A. Carbohydrate metabolism, B. Sphingolipid metabolism, C. Lysophospholipids metabolism, D. Fatty acid metabolism, E. Other (Key: "non-allergic": white square, "mild": light grey square, "moderate": grey square, "severe": dark grey square). The central box covers the interquartile range with the median indicated by the line within the box and the mean of each experimental group is represented by " $X$ ". The whiskers extend to the minimum and maximum values and outliers values are shown individually. ${ }^{* *} U$ Mann Whitney $p$-value $<0.01 . * U$ Mann Whitney $p$-value $<0.05$.

Figure 3. Statistically significant transcript differences between experimental groups. A. Genes differentially expressed among the phenotypes. Red bars represent upregulated genes in the first group of the comparison and blue bars the downregulated genes of the second group. B. Venn diagrams representing the differences in each group against the rest: "non-allergic vs mild" (blue), "non-allergic vs moderate" (red), "non-allergic vs severe" (brown), "mild vs moderate" (yellow) and "moderate vs severe" (purple). C. Heatmap of the 100 top differentially expressed genes. Upregulated genes are represented in red and downregulated are shown in blue. ANOVA $p$-value $<0.05$

Figure 4. Trajectories of significant transcripts associated with platelet functions. A. Adhesion, B. Activation, C. Receptor Occupancy, D. Shape Change, E. Secretion, F. Aggregation, G. Other (Key: "non-allergic": white square, "mild": light grey square, "moderate": grey square, "severe": dark grey square) $95 \%$ confidence interval limits for the mean (central circle) of each experimental group are indicated ** ANOVA $p$-value $<0.001 . *$ ANOVA $p$-value $<0.05$.

This article is protected by copyright. All rights reserved. 
Figure 5. Schematic representation of the proposed platelet dysfunction mechanism in "severe" phenotype. Molecules and functions represented in blue are diminished: decreased metabolites and downregulated transcripts are represented in light blue. Molecules indirectly associated with transcripts are represented in dark blue and marked with a down arrow. Increased metabolites are marked in red. All functions are divided by blue lines and their associated downregulated transcripts are shown in a blue ellipse. Platelet-activation pathways are included in a light blue circle. Abbreviations: T-R: "Thrombopoietin Receptor", Gq="G-Protein Receptor", TK="Tyrosin Kinase Receptor", PKC- $\theta=$ "Protein Kinase C $\theta$ ), PLC="Phospholipase C", IP3=“Inositol triphosphate", MLC="Myosin Light Chain Protein", CO="Cyclooxygenase", LO="Lypoxygenase", PGG2=“Prostaglandin G2", PGH2=“Prostaglandin H2", 12-HETE=“12-Hydroxyeicosatetraenoic acid”, $\alpha G=$ "Alpha granules", $\delta G=$ "Dense granules", Vs="Vesicles", GP= "Glycoprotein", SPHK1/2="Sphingosine Kinase 1/2", LPP="lipid phosphate phosphatase", ABC="ABC transporter", vWF="Von Willebrand Factor".

Figure 1S. Unsupervised PCA models showing the quality of the data for the three techniques. (Key:

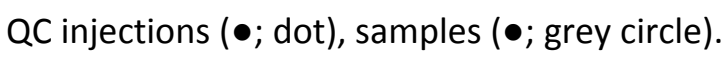

Figure 2S. PLS DA models for each pairwise comparison in the three complementary techniques. (Key: "non-allergic": circle, "mild": square, "moderate": pentagon, "severe": triangle). Data was Log transform and centre scaled. ${ }^{*}$ Characters in bold pointed out suitable quality parameters $(Q 2>0.5)$ for the model.

Figure 3S. Significant signals between "mild vs severe" and "moderate vs severe" groups were depicted on heatmaps using hierarchical clustering of the samples. Kruskal-Wallis test was used to detect statistical significance $(p<0.05)$.

Figure 4S. Validation of microarray data by qPCR using $2-\Delta \Delta C T$ method. Microarray results in white are shown compared to $\mathrm{qPCR}$ results in black. Standard deviation bars are represented in qPCR results.

This article is protected by copyright. All rights reserved. 


\section{REFERENCES}

1. Matricardi PM, Kleine-Tebbe J, Hoffmann HJ, Valenta R, Hilger C, Hofmaier S et al. EAACI Molecular Allergology User's Guide. Pediatr Allergy Immunol 2016; 27 Suppl 23:1-250. 2. Barber D, de la Torre F, Feo F, Florido F, Guardia P, Moreno C et al. Understanding patient sensitization profiles in complex pollen areas: a molecular epidemiological study. Allergy 2008; 63:1550-8.

3. Barber D, Diaz-Perales A, Villalba M, Chivato T. Challenges for allergy diagnosis in regions with complex pollen exposures. Curr Allergy Asthma Rep 2015 Feb;15(2):496.

4. Barber D, de la Torre F, Lombardero M, Antepara I, Colas C, Davila I, et al. Component-resolved diagnosis of pollen allergy based on skin testing with profilin, polcalcin and lipid transfer protein pan-allergens. Clin Exp Allergy 2009 Nov;39(11):1764-73.

5. Barber D, Moreno C, Ledesma A, Serrano P, Galan A, Villalba M et al. Degree of olive pollen exposure and sensitization patterns. Clnical implications. J Investig Clin Immunol 2007; 17 Suppl 1: 11-6.

6. Alvarado MI, Jimeno L, De La Torre F, Boissy P, Rivas B, Lazaro MJ, et al. Profilin as a severe food allergen in allergic patients overexposed to grass pollen. Allergy 2014 Dec;69(12):1610-6.

7. Ruiz-Garcia M, Garcia Del Potro M, Fernandez-Nieto M, Barber D, Jimeno-Nogales L, Sastre J. Profilin: a relevant aeroallergen? J Allergy Clin Immunol 2011 Aug;128(2):416-8.

8. Rodríguez Del Río P, Díaz-Perales A, Sánchez-García S, Escudero C, Ibáñez MD, Méndez-Brea $\mathrm{P}$, et al. Profilin, a Change in the Paradigm. J Investig Allergol Clin Immunol 2018;28(1):1-12.

9. Lund $G$, Brand $S$, Ramos $T$, Jimeno L, Boissy $P$, Vega $F$, et al. Strong and frequent Tcell responses to the minor allergen Phl p 12 in Spanish patients IgE-sensitized to Profilins. Allergy 2017 Nov 9.

10. Rosace $D$, Gómez-Casado $C$, Fernández $P$, Pérez-Gordo $M$, Domínguez $M$, Vega $A$, et al. Profilin-mediated food allergic reactions are associated with oral epithelial remodeling. $J$ Allergy Clin Immunol. 2018 Apr 27. pii: S0091-6749(18)30611-0.

11. Conway SJ, Izuhara K, Kudo Y, Litvin J, Markwald R, Ouyang G, et al. The role of periostin in tissue remodeling across health and disease. Cellular and Molecular Life Siciences 2014;71:1279-88

12. Papadopoulos NG, Agache I, Bavbek S, Bilo BM, Braido F, Cardona V, et al.Research needs in allergy: an EAACl position paper, in collaboration with EFA. Clin Transl Allergy. 2012 Nov 2;2(1):21.

This article is protected by copyright. All rights reserved. 
13. Blanchard C, Mingler MK, Vicario M, Abonia JP, Wu YY, Lu TX, et al. IL-13 involvement in eosinophilic esophagitis: transcriptome analysis and reversibility with glucocorticoids. $J$ Allergy Clin Immunol 2007 Dec;120(6):1292-300.

14. Tsitsiou E, Williams AE, Moschos SA, Patel K, Rossios C, Jiang X, et al. Transcriptome analysis shows activation of circulating CD8+ T cells in patients with severe asthma. J Allergy Clin Immunol 2012 Jan;129(1):95-103.

15. Choy DF, Hsu DK, Seshasayee D, Fung MA, Modrusan Z, Martin F, et al. Comparative transcriptomic analyses of atopic dermatitis and psoriasis reveal shared neutrophilic inflammation. J Allergy Clin Immunol 2012 Dec;130(6):1335-43 e5.

16. Kosoy R, Agashe C, Grishin A, Leung DY, Wood RA, Sicherer SH, et al. Transcriptional Profiling of Egg Allergy and Relationship to Disease Phenotype. PLoS One 2016 Oct 27;11(10):e0163831.

17. Villaseñor $A$, Rosace $D$,Obeso $D$, Pérez-Gordo $M$, Chivato $T$, Barbas $C$, Barber $D$, Escribese MM. Allergic asthma: an overview of metabolomic strategies leading to the identification of biomarkers in the field.Clin Exp Allergy 2017;47: 442-56.

18. Sokolowska M, Chen LY, Liu Y, Martinez-Anton A, Logun C, Alsaaty S, et al. Dysregulation of lipidomic profile and antiviral immunity in response to hyaluronan in patients with severe asthma. J Allergy Clin Immunol. 2017 Apr;139(4):1379-1383.

19. Rodriguez-Perez N, Schiavi E, Frei R, Ferstl R, Wawrzyniak P, Smolinska S, et al. Altered fatty acid metabolism and reduced stearoyl-coenzyme a desaturase activity in asthma. Allergy. 2017 Nov;72(11):1744-1752.

20. Singh A, Yamamoto M, Kam SH, Ruan J, Gauvreau GM, O'Byrne PM, et al. Genemetabolite expression in blood can discriminate allergen-induced isolated early from dual asthmatic responses. PLoS One. 2013 Jul 2;8(7):e67907.

21. Ciborowski M, Javier Rupérez F, Martínez-Alcázar MP, Angulo S, Radziwon P, Olszanski R, et al. Metabolomic approach with LC-MS reveals significant effect of pressure on diver's plasma. J Proteome Res 2010 Aug 6;9(8):4131-7

22. Garcia A, Barbas C. Gas Chromatography-Mass Spectrometry (GC-MS)-Based Metabolomics. Methods in molecular biology 2011; 708: 191-204.

23. Triba MN, Le Moyec L, Amathieu R, Goossens C, Bouchemal N, Nahon P, et al. PLS/OPLS models in metabolomics: the impact of permutation of dataset rows on the K-fold cross-validation quality parameters. Mol Biosyst 2015 Jan; 11(1):13-9.

24. Worley B, Powers R. PCA as a practical indicator of OPLS-DA model reliability. Curr Metabolomics 2016; 4(2):97-103.

This article is protected by copyright. All rights reserved. 
25. Brown M, Dunn WB, Ellis DI, Goodacre R, Handl J, Knowles JD, Kell DB. A metabolome pipeline: from concept to data to knowledge. Metabolomics 2005;1: 39.

26. Livak KJ, Schmittgen TD. Analysis of relative gene expression data using real-time quantitative PCR and the 2(-Delta Delta C(T)) Method. Methods. 2001; Dec;25(4):402-8.

27. Bylesjö $M$, Rantalainen $M$, Cloarec $O$, Nicholson JK, Holmes E, Trygg J. OPLS discriminant analysis: Combining the strengths of PLS-DA and SIMCA classification. Journal of Chemometrics 2006; 20(8-10), 341-351.

28. Loza MJ, Djukanovic R, Chung KF, Horowitz D, Ma K, Branigan P, Baribaud F. Validated and longitudinally stable asthma phenotypes based on cluster analysis of the ADEPT study. Respiratory Research 2016; 17(1), 165.

29. Sallis BF, Erkert L, Moñino-Romero S, Acar U, Wu R, Konnikova L, Fiebiger E. An algorithm for the classification of mRNA patterns in eosinophilic esophagitis: Integration of machine learning. Journal of Allergy and Clinical Immunology 2018.

30. Kuo CHS, Pavlidis S, Loza M, Baribaud F, Rowe A, Pandis I, Chung KF. A transcriptome-driven analysis of epithelial brushings and bronchial biopsies to define asthma phenotypes in U-BIOPRED. American Journal of Respiratory and Critical Care Medicine 2017; 195(4), 443-455.

31. Horiuchi H, Shirakawa R, Yasumi T. Molecular mechanism of granule secretion from platelet. Rinsho Ketsueki 2012 Jul;53(7):664-71.

32. Washington AV, Gibot S, Acevedo I, Gattis J, Quigley L, Feltz R, et al. TREM-like transcript-1 protects against inflammation-associated hemorrhage by facilitating platelet aggregation in mice and humans. J Clin Invest 2009 Jun;119(6):1489-501.

33. Schenk BI, Petersen F, Flad HD, Brandt E. Platelet-derived chemokines CXC chemokine ligand $(\mathrm{CXCL}) 7$, connective tissue-activating peptide III, and CXCL4 differentially affect and cross-regulate neutrophil adhesion and transendothelial migration. J Immunol 2002 Sep 1;169(5):2602-10.

34. Gnatenko DV, Dunn JJ, McCorkle SR, Weissmann D, Perrotta PL, Bahou WF. Transcript profiling of human platelets using microarray and serial analysis of gene expression. Blood 2003 Mar 15;101(6):2285-93.

35. Nowak-Wegrzyn A, Assa'ad AH, Bahna SL, Bock SA, Sicherer SH, Teuber SS. Work Group report: oral food challenge testing. J Allergy Clin Immunol 2009;123:S365-83.

36. Costa V, Casamassimi A, Roberto R, Gianfrancesco F, Matarazzo MR, D'Urso M, et al. DDX11L: a novel transcript family emerging from human subtelomeric regions. $B M C$ Genomics 2009 May 28;10:250.

This article is protected by copyright. All rights reserved. 
37. Loftus RM, Finlay DK. Immunometabolism: Cellular Metabolism Turns Immune Regulator. J Biol Chem 2016;291(1):1-10.

38. O'Neill LA, Kishton RJ, Rathmell J. A guide to immunometabolism for immunologists. Nat Rev Immunol 2016;16(9):553-65.

39. Ostroukhova M, Goplen N, Karim MZ, Michalec L, Guo L, Liang Q, Alam R. The role of low-level lactate production in airway inflammation in asthma. Am J Physiol Lung Cell Mol Physiol 2012 Feb 1;302(3):L300-7.

40. Rodrigo GJ, Rodrigo C. Elevated plasma lactate level associated with high dose inhaled albuterol therapy in acute severe asthma. Emerg Med J 2005; 22: 404-408.

41. Shime H, Yabu M, Akazawa T, Kodama K, Matsumoto M, Seya T, Inoue N. Tumorsecreted lactic acid promotes IL-23/IL-17 proinflammatory pathway. J Immunol 2008; 180: 7175-7183.

42. Arita, M. Eosinophil polyunsaturated fatty acid metabolism and its potential control of inflammation and allergy. Allergology International 2016; 65: S2-S5.

43. Bennett M, Gilroy DW. Lipid Mediators in Inflammation. Microbiology Spectrum 2016; 4(6):1-21.

44. Abdullah E, Idris A, Saparon A. Papr reduction using scs-sIm technique in stfbc mimoofdm. ARPN Journal of Engineering and Applied Sciences 2017; 12(10): 3218-3221.

45. Kulinski JM, Muñoz-Cano R, Olivera A. Sphingosine-1-phosphate and other lipid mediators generated by mast cells as critical players in allergy and mast cell function. Eur J Pharmacol 2016;778:56-67.

46. Saradna A, Do DC, Kumar S, Fu QL, Gao P. (2018). Macrophage polarization and allergic asthma. Translational Research 2018; 191:1-14.

47. Rumbaut RE, Thiagarajan P. Platelet-Vessel Wall Interactions in Hemostasis and Thrombosis. San Rafael (CA): Morgan \& Claypool Life Sciences; 2010. Chapter 3, Platelet Adhesion to Vascular Walls.

48. Rumbaut RE, Thiagarajan P. Platelet-Vessel Wall Interactions in Hemostasis and Thrombosis. San Rafael (CA): Morgan \& Claypool Life Sciences; 2010. Chapter 4, Platelet Aggregation.

49. McCulloch RK, Croft KD, Vandongen R. Enhancement of platelet 12-HETE production in the presence of polymorphonuclear leukocytes during calcium ionophore stimulation. Biochim Biophys Acta 1992 Jan 13; 1133(2):142-6.

50. Baig A, Bao X, Wolf $M$, Haslam RJ. The platelet protein kinase $C$ substrate pleckstrin binds directly to SDPR protein. Platelets 2009 Nov;20(7):446-57.

This article is protected by copyright. All rights reserved. 
51. Aburima A, Wraith KS, Raslan Z, Law R, Magwenzi S, Naseem KM. cAMP signaling regulates platelet myosin light chain (MLC) phosphorylation and shape change through targeting the RhoA-Rho kinase-MLC phosphatase signaling pathway. Blood 2013 Nov 14;122(20):3533-45 .

52. Lee-Sarwar K, Kelly RS, Lasky-Su J, Moody DB, Mola AR, Cheng TY, et al. Intestinal microbial-derived sphingolipids are inversely associated with childhood foodallergy. J Allergy Clin Immunol. 2018 May 2. pii: S0091-6749(18)30628-6.

53. Vito CD, Hadi LA, Navone SE, Marfia G, Campanella R, Mancuso ME, et al. Plateletderived sphingosine-1-phosphate and inflammation: from basic mechanisms to clinical implications. Platelets 2016;27(5):393-401.

54. Wedman PA, Aladhami A, Chumanevich AP, Fuseler JW, Oskeritzian CA. Mast cells and sphingosine-1-phosphate underlie prelesional remodeling in a mouse model of eczema. Allergy 2018 Feb;73(2):405-415.

55. Trinh HK, Kim SC, Cho K, Kim SJ, Ban GY, Yoo HJ, et al. Exploration of the Sphingolipid Metabolite, Sphingosine-1-phosphate and Sphingosine, as Novel Biomarkers for Aspirinexacerbated Respiratory Disease. Sci Rep 2016 Nov 10; 6:36599.

56. Oskeritzian CA, Hait NC, Wedman P, Chumanevich A, Kolawole EM, Price MM, et al. The sphingosine-1-phosphate/sphingosine-1-phosphate receptor 2 axis regulates early airway T-cell infiltration in murine mast cell-dependent acute allergic responses. J Allergy Clin Immunol 2015 Apr;135(4):1008-18.e1.

57. Książek M, Chacińska M, Chabowski A, Baranowski M. Sources, metabolism, and regulation of circulating sphingosine-1-phosphate. Journal of Lipid Research 2015; 56(7): 1271-1281.

58. Ried JS, Baurecht H, Stückler F, Krumsiek J, Gieger C, Heinrich J, et al. Integrative genetic and metabolite profiling analysis suggests altered phosphatidylcholine metabolism in asthma. Allergy 2013; 68:629-36.

59. Jung J, Kim SH, Lee HS, Choi GS, Jung YS, Ryu DH, et al. Serum metabolomics reveals pathways and biomarkers associated with asthma pathogenesis. Clin Exp Allergy 2013; 43:425-33.

60. Comhair SA, McDunn J, Bennett C, Fettig J, Erzurum SC, Kalhan SC. Metabolomic endotype of asthma. J Immunol 2015; 195:643-50.

61. Rumbaut RE, Thiagarajan P. Platelet-Vessel Wall Interactions in Hemostasis and Thrombosis. San Rafael (CA): Morgan \& Claypool Life Sciences; 2010. Chapter 5, Platelet Activation.

This article is protected by copyright. All rights reserved. 
62. Lefrançais E, Ortiz-Muñoz G, Caudrillier A, Mallavia B, Liu F, Sayah DM, et al. The lung is a site of platelet biogenesis and a reservoir for haematopoietic progenitors. Nature. 2017 Apr 6;544(7648):105-109.

63. Willemsen LE. Dietary $n-3$ long chain polyunsaturated fatty acids in allergy prevention and asthma treatment. Eur J Pharmacol 2016;785:174-186.

64. Kumar A, Mastana SS, Lindley MR. n-3 Fatty acids and asthma. Nutr Res Rev 2016;29:1-16.

65. Giudetti AM, Cagnazzo R. Beneficial effects of n-3 PUFA on chronic airway inflammatory diseases. Prostaglandins Other Lipid Mediat 2012;99:57-67.

66. Amison RT, Cleary S, Riffo-Vasquez Y, Bajwa M, Page CP, Pitchford SC. Platelets Play a Central Role in Sensitization to Allergen. Am J Respir Cell Mol Biol 2018 Jan 24.

67. Takeda $\mathrm{T}$, Unno H, Morita H, Futamura K, Emi-Sugie M, Arae K, et al. Platelets constitutively express IL-33 protein and modulate eosinophilic airway inflammation. J Allergy Clin Immunol 2016 Nov;138(5):1395-403 e6.

68. Idzko M, Pitchford S, Page C. Role of platelets in allergic airway inflammation. J Allergy Clin Immunol 2015 Jun;135(6):1416-23.

69. Morrell CN, Aggrey AA, Chapman LM, Modjeski KL. Review Article Emerging roles for platelets as immune and in fl ammatory cells. Blood 2014; 123(18): 2759-2767.

70. Shah SA, Page CP, Pitchford SC. Platelet-Eosinophil Interactions As a Potential Therapeutic Target in Allergic Inflammation and Asthma. Frontiers in Medicine 2017; 4(August).

71. Wojtukiewicz MZ, Sierko E, Hempel D, Tucker SC, Honn KV. Platelets and cancer angiogenesis nexus. Cancer and Metastasis Reviews 2017; 36(2):249-262.

This article is protected by copyright. All rights reserved. 
Table 1. IPA significant results for "severe versus mild" and "severe versus moderate" comparison. The functions were ranked by $p$-value.

\section{A. SEVERE VS MILD}

Categories

Diseases or Functions Annotation p-Value

Activation z-

score*

Cell-To-Cell Signaling and Interaction, Hematological System Development and Function, Inflammatory Response, Organismal Functions

Cell-To-Cell Signaling and Interaction, Hematological System Development and Function, Inflammatory Response

Cell-To-Cell Signaling and Interaction

Cardiovascular System Development and Function, Cell-To-Cell Signaling and Interaction

Cell-To-Cell Signaling and Interaction, Cellular Function and Maintenance, Hematological

System Development and Function, Inflammatory Response

Activation of blood platelets

$1,01 \mathrm{E}-05$

$-1.091$

Binding of blood platelets

1,07E-04

$-1.019$

Binding of blood cells

1,90E-04

$-0.605$

8

Binding of endothelial cells

2,15E-04

$-1.095$

6

Cell-To-Cell Signaling and Interaction, Cellular Function and Maintenance, Inflammatory

Response

Phagocytosis of blood platelets

$2,55 \mathrm{E}-04$

Phagocytosis of blood cells

$2,58 \mathrm{E}-04$

$-1.103$

4

Cellular Movement

Chemotaxis

3,58E-04

$-0.919$

9

Cellular Movement, Immune Cell Trafficking

Leukocyte migration

3,76E-04

$-0.505$

10

Cardiovascular System Development and Function, Cell-To-Cell Signaling and Interaction

Adhesion of endothelial cells

$3,85 \mathrm{E}-04$

$-1.079$

5

Cell-To-Cell Signaling and Interaction, Hematological System Development and Function, Inflammatory Response

Adhesion of blood platelets

$4,52 \mathrm{E}-04$

Cell-To-Cell Signaling and Interaction

Aggregation of cells

$9,58 \mathrm{E}-04$

$-0.556$

6

Cell-To-Cell Signaling and Interaction, Hematological System Development and Function

Cell-To-Cell Signaling and Interaction, Hematological System Development and Function

Aggregation of blood cells

9,83E-04

$-0.783$

5

Activation of blood cells

1,22E-03

$-2.021$

9

This article is protected by copyright. All rights reserved. 


\begin{tabular}{|c|c|c|c|c|}
\hline Cardiovascular System Development and Function, Organismal Development & Angiogenesis & $1,43 \mathrm{E}-03$ & -1.294 & 10 \\
\hline Cell Morphology, Hematological System Development and Function & Conversion of blood cells & $1,51 \mathrm{E}-03$ & & 2 \\
\hline Cardiovascular System Development and Function, Cellular Movement & $\begin{array}{l}\text { Cell movement of endothelial } \\
\text { cells }\end{array}$ & $1,63 \mathrm{E}-03$ & -1.404 & 7 \\
\hline Tissue Development & Accumulation of cells & $1,70 \mathrm{E}-03$ & 0.243 & 4 \\
\hline Carbohydrate Metabolism & Metabolism of glycogen & $1,74 \mathrm{E}-03$ & & 2 \\
\hline Cardiovascular System Development and Function, Cellular Movement & $\begin{array}{l}\text { Movement of vascular } \\
\text { endothelial cells }\end{array}$ & 2,01E-03 & -0.849 & 5 \\
\hline $\begin{array}{l}\text { Cell-To-Cell Signaling and Interaction, Cellular Movement, Hematological System } \\
\text { Development and Function, Immune Cell Trafficking }\end{array}$ & Recruitment of leukocytes & $2,45 \mathrm{E}-03$ & & 4 \\
\hline \multicolumn{5}{|l|}{ B. SEVERE VS MODERATE } \\
\hline Categories & Diseases or Functions Annotation & p-Value & $\begin{array}{l}\text { Activation Z- } \\
\text { score* }\end{array}$ & $n^{8}$ \\
\hline $\begin{array}{l}\text { Cell-To-Cell Signaling and Interaction, Hematological System Development and Function, } \\
\text { Inflammatory Response }\end{array}$ & Binding of blood platelets & $3,19 E-12$ & $-2,369$ & 9 \\
\hline Cell-To-Cell Signaling and Interaction & Binding of blood cells & $6,75 \mathrm{E}-11$ & $-3,219$ & 15 \\
\hline Cell-To-Cell Signaling and Interaction & Adhesion of blood cells & $1,44 \mathrm{E}-10$ & $-2,932$ & 14 \\
\hline $\begin{array}{l}\text { Cell-To-Cell Signaling and Interaction, Hematological System Development and Function, } \\
\text { Inflammatory Response }\end{array}$ & Adhesion of blood platelets & $1,52 \mathrm{E}-10$ & $-1,632$ & 7 \\
\hline Cell-To-Cell Signaling and Interaction, Hematological System Development and Function & Aggregation of blood cells & $3,20 \mathrm{E}-10$ & $-2,521$ & 11 \\
\hline $\begin{array}{l}\text { Cell-To-Cell Signaling and Interaction, Hematological System Development and Function, } \\
\text { Inflammatory Response }\end{array}$ & Aggregation of blood platelets & $5,19 \mathrm{E}-10$ & $-2,298$ & 10 \\
\hline Hematological System Development and Function & Hemostasis & 4,38E-09 & $-2,107$ & 10 \\
\hline
\end{tabular}

This article is protected by copyright. All rights reserved. 


\begin{tabular}{|c|c|c|c|c|}
\hline $\begin{array}{l}\text { Cell-To-Cell Signaling and Interaction, Hematological System Development and Function, } \\
\text { Inflammatory Response, Organismal Functions }\end{array}$ & Activation of blood platelets & $1,75 \mathrm{E}-08$ & $-1,318$ & 7 \\
\hline Cardiovascular System Development and Function, Cell-To-Cell Signaling and Interaction & $\begin{array}{l}\text { Binding of vascular endothelial } \\
\text { cells }\end{array}$ & 2,29E-06 & $-2,620$ & 7 \\
\hline Cardiovascular System Development and Function, Cell-To-Cell Signaling and Interaction & Binding of endothelial cells & $2,68 \mathrm{E}-06$ & $-2,170$ & 8 \\
\hline Cardiovascular System Development and Function, Cell-To-Cell Signaling and Interaction & Adhesion of endothelial cells & $3,31 \mathrm{E}-06$ & $-1,563$ & 7 \\
\hline $\begin{array}{l}\text { Cellular Movement, Hematological System Development and Function, Immune Cell } \\
\text { Trafficking, Inflammatory Response }\end{array}$ & Infiltration by neutrophils & 3,39E-06 & $-2,159$ & 5 \\
\hline Cardiovascular System Development and Function, Cellular Movement & $\begin{array}{l}\text { Chemotaxis of vascular } \\
\text { endothelial cells }\end{array}$ & $3,67 \mathrm{E}-06$ & $-1,934$ & 4 \\
\hline $\begin{array}{l}\text { Cellular Movement, Hematological System Development and Function, Immune Cell } \\
\text { Trafficking }\end{array}$ & Cell rolling of leukocytes & $7,83 \mathrm{E}-06$ & & 4 \\
\hline Cellular Movement & $\begin{array}{l}\text { Arrest in cell movement of } \\
\text { myeloid cells }\end{array}$ & $8,86 \mathrm{E}-06$ & & 3 \\
\hline $\begin{array}{l}\text { Cellular Movement, Hematological System Development and Function, Immune Cell } \\
\text { Trafficking, Inflammatory Response }\end{array}$ & Cell rolling of phagocytes & $8,86 \mathrm{E}-06$ & & 3 \\
\hline $\begin{array}{l}\text { Cellular Movement, Hematological System Development and Function, Immune Cell } \\
\text { Trafficking, Inflammatory Response }\end{array}$ & Cell movement of neutrophils & $8,91 \mathrm{E}-06$ & $-2,541$ & 7 \\
\hline $\begin{array}{l}\text { Cell-To-Cell Signaling and Interaction, Hematological System Development and Function, } \\
\text { Immune Cell Trafficking, Inflammatory Response }\end{array}$ & Adhesion of neutrophils & $9,21 \mathrm{E}-06$ & $-2,177$ & 5 \\
\hline Immunological Disease & Allergy & $1,05 \mathrm{E}-05$ & & 10 \\
\hline Cell-To-Cell Signaling and Interaction, Hematological System Development and Function & Activation of blood cells & $1,45 \mathrm{E}-05$ & $-2,620$ & 12 \\
\hline Cellular Assembly and Organization & Binding of cytoskeleton & $1,62 \mathrm{E}-05$ & & 3 \\
\hline
\end{tabular}

NOTE: The source was IPA for all categories.

*: statistical value based on the match between expected relationship and observed gene expression that predicts the activation state of pathways (positive-activation; negative-inactivation) . \& \& $\quad$ \&umber of significant genes present in the pathway.

This article is protected by copyright. All rights reserved. 

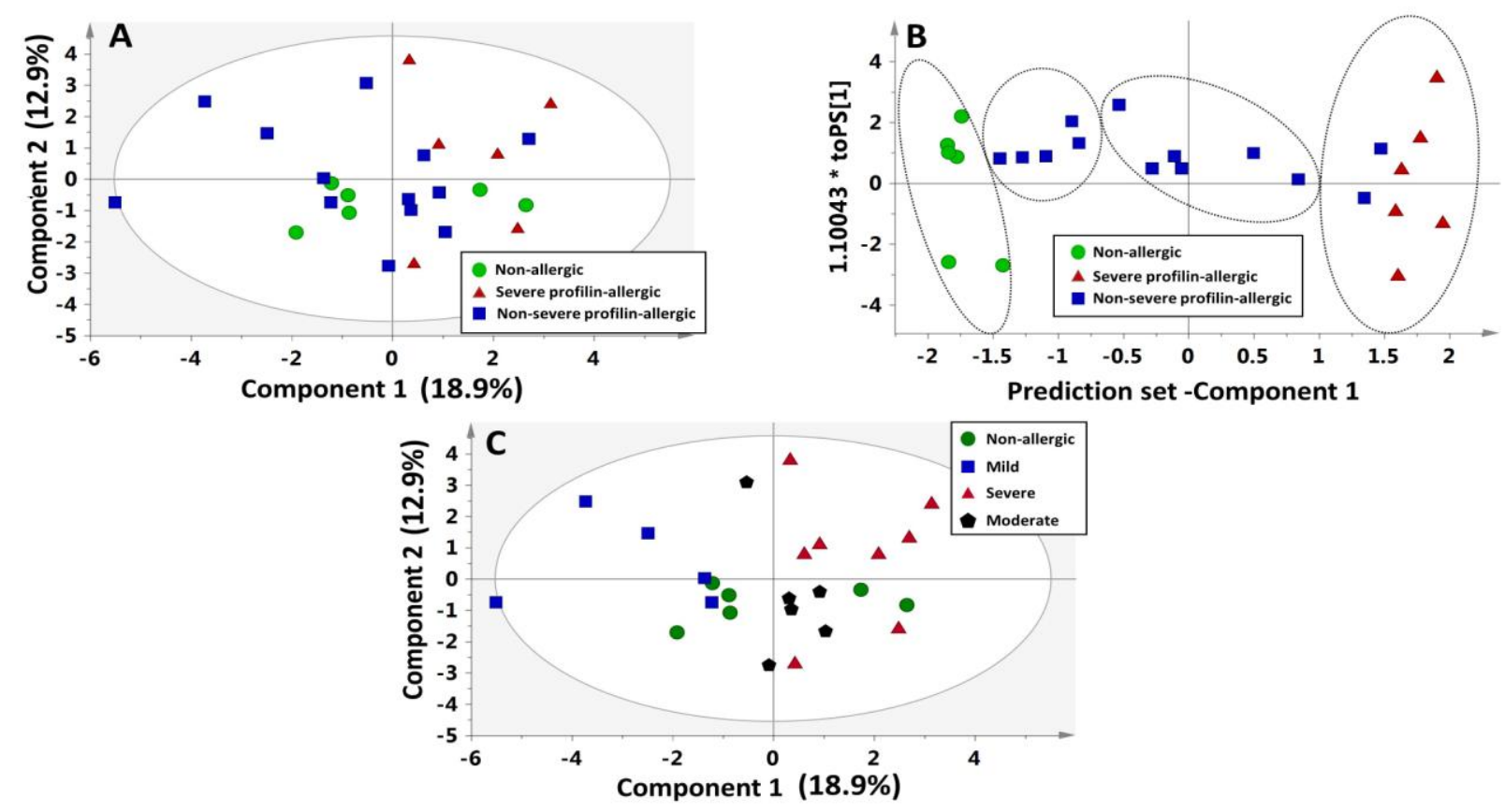

A
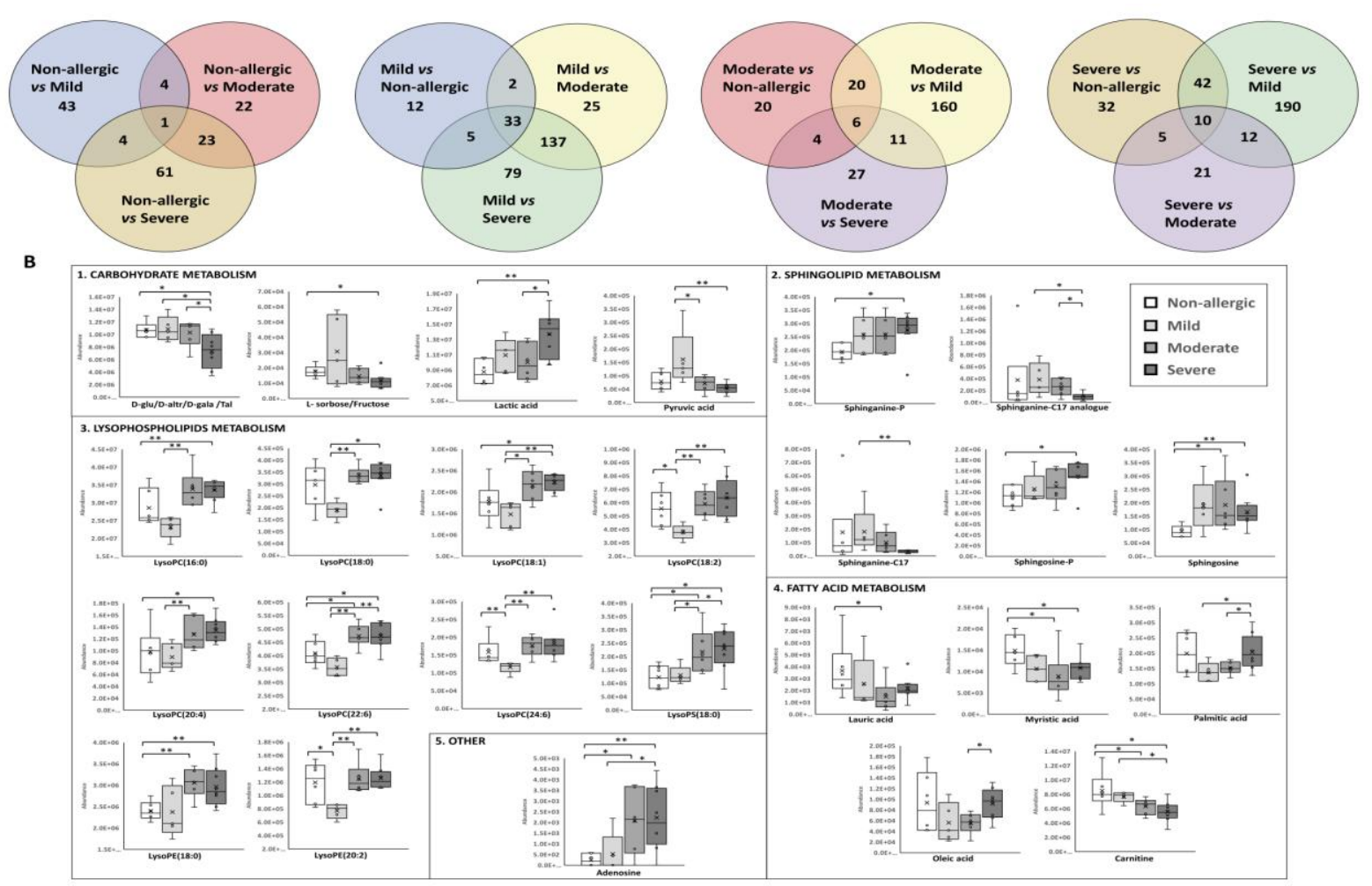

This article is protected by copyright. All rights reserved. 


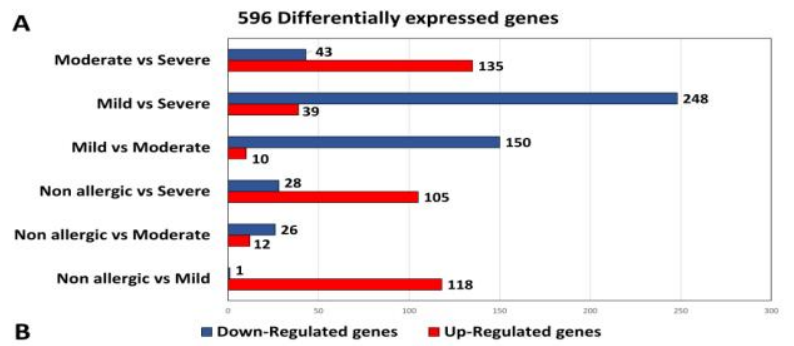

C
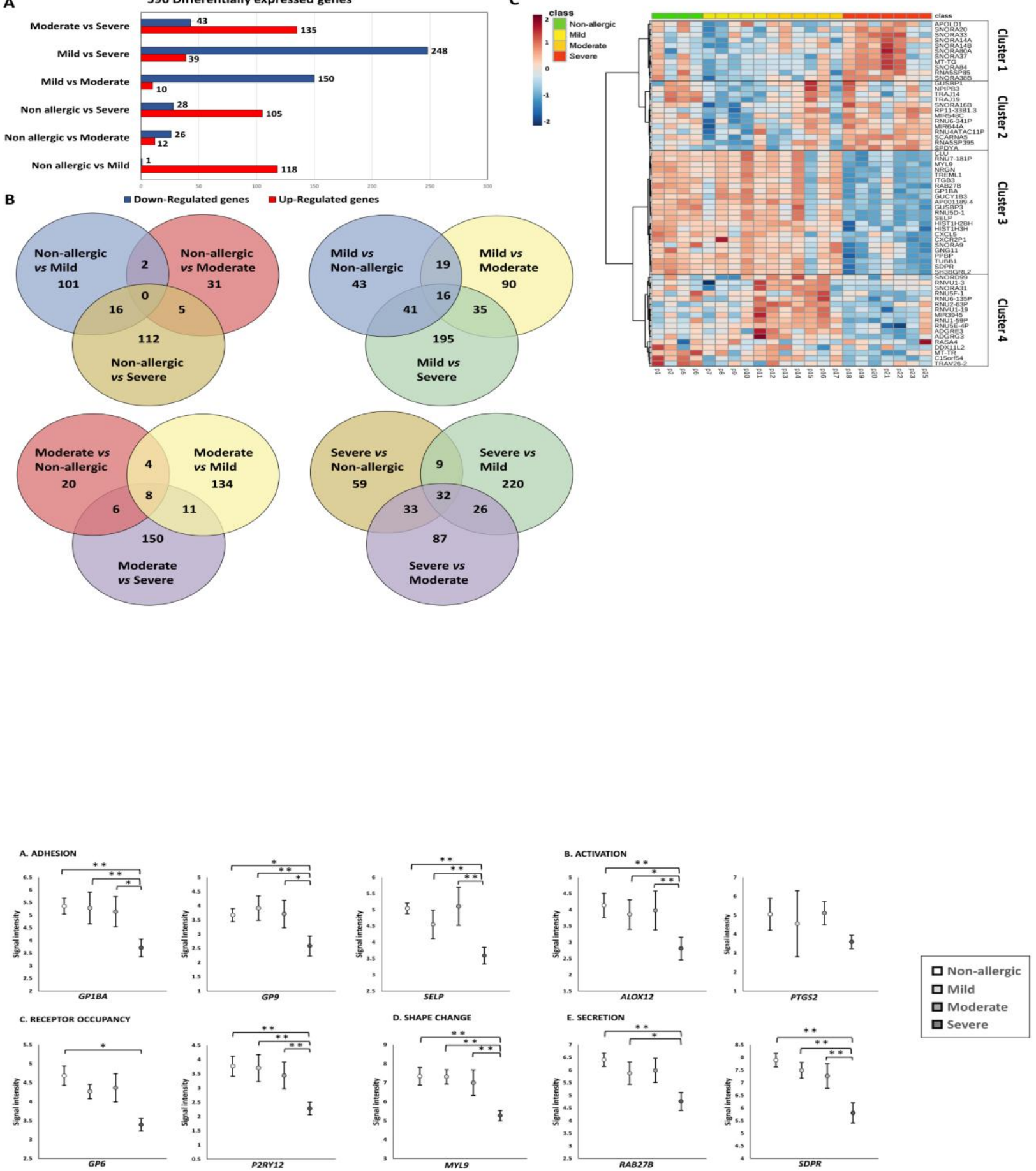

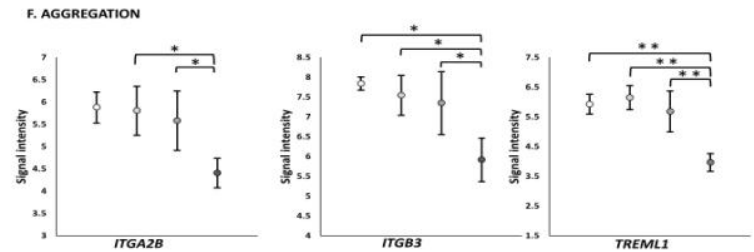
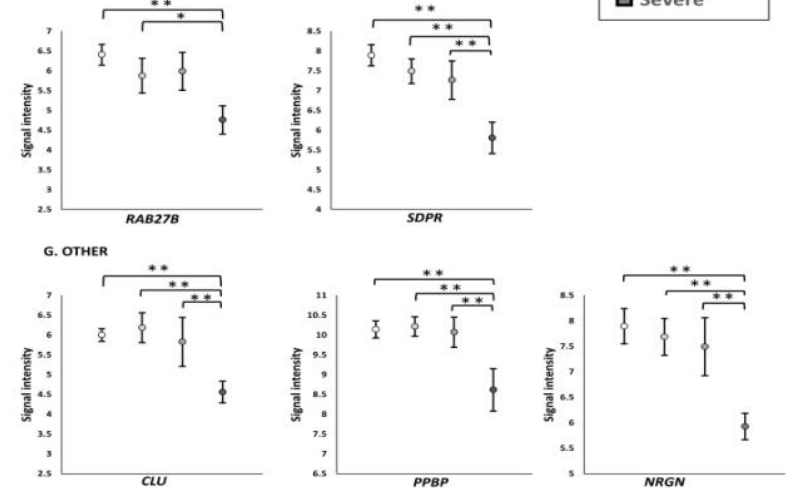

This article is protected by copyright. All rights reserved. 


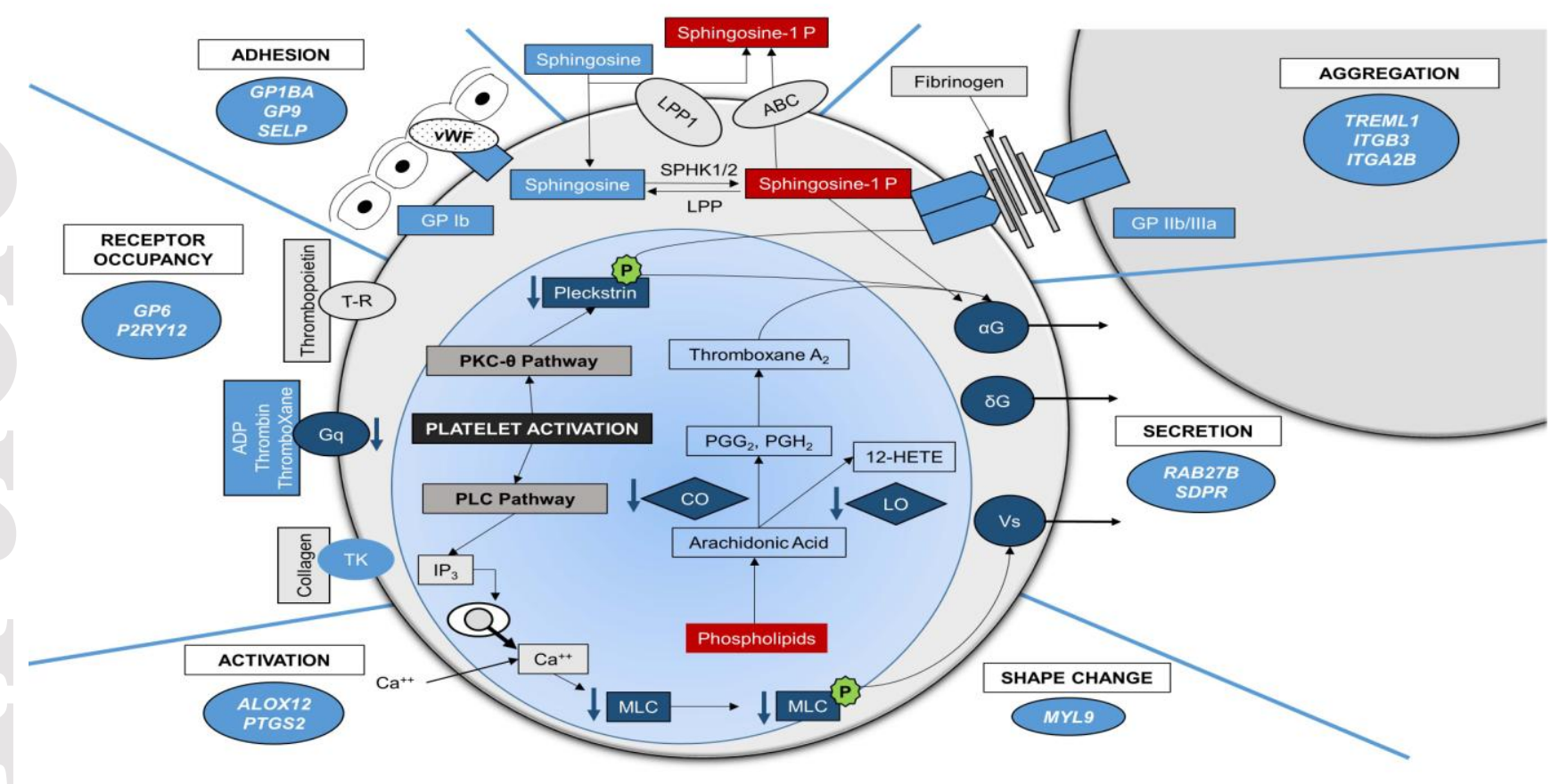

This article is protected by copyright. All rights reserved. 